Ege Tıp Dergisi/Ege Journal of Medicine 2018;57(4):232-237

\title{
Santral venöz portların çıkarııma nedenleri: Ardışık 154 hastadan edinilen deneyim
}

\author{
Reasons for removal of central venous ports: Experience with 154 consecutive \\ patients \\ Fatih Uzunkaya $^{1} \quad$ Ayşegül İil Soylu $^{1} \quad$ Ümit Belet ${ }^{1} \quad$ Özlem Terzi ${ }^{2} \quad$ Hüseyin Akan ${ }^{1}$ \\ ${ }^{1}$ Ondokuz Mayıs Üniversitesi Tıp Fakültesi, Radyoloji Anabilim Dalı, Samsun, Türkiye \\ ${ }^{2}$ Ondokuz Mayıs Üniversitesi Tıp Fakültesi, Halk Sağlığı Anabilim Dalı, Samsun, Türkiye
}

\section{Öz}

Amaç: Bu çalışmanın amacı, tek merkezde santral venöz portların çıkarılma nedenlerinin sıklıklarını tespit etmek, port kaynaklı enfeksiyon ile ilişkili risk faktörlerini ve portların açık kaldığı süreyi etkileyen faktörleri belirlemektir.

Gereç ve Yöntem: Ocak 2005 - Mayıs 2017 tarihleri arasında port çıkarma işlemi yapılmış 154 hasta çalışmaya dahil edildi. Hastaların yaş ve cinsiyetleri, klinik tanıları, portlarının çıkarılma nedenleri, mikrobiyolojik test sonuçları ve portlarının açık kaldığı süreler retrospektif olarak araştırıldı. Port kaynaklı enfeksiyon ile ilişkili risk faktörlerini karşılaştırmak için Ki-kare testi, portların açık kaldığı süreyi etkileyen faktörleri karşılaştırmak için ise Mann-Whitney $U$ testi kullanıldı.

Bulgular: Hastaların \%51,3'ü kadın, \%48,7'si erkekti (yaş ortalaması 55,1 \pm 15 ). Portların en sık (\%53,2) enfeksiyon gerekçesiyle çıkarıldığı tespit edildi. Cinsiyetin, yaşın, malignite tipinin ve sindirim kanalı kanserine sahip olmanın enfeksiyon sıklığını anlamlı derecede etkilemediği belirlendi. Enfeksiyon gelişen hastaların kültürlerinde en sık $(\% 20,9)$ izole edilen patojenin Staphylococcus aureus olduğu görüldü. Cinsiyetin, yaşın, malignite tipinin ve sindirim kanalı kanserine sahip olmanın portların açık kaldığı süreyi anlamlı derecede etkilemediği, buna karşın enfeksiyonun bu süreyi önemli ölçüde kısalttığı tespit edildi.

Sonuç: Kanser hastalarının yarısından fazlasının portu enfeksiyon nedeniyle çıkarılmaktadır. Enfeksiyon, portların açık kaldığı süreyi önemli ölçüde kısaltmaktadır.

Anahtar Sözcükler: Santral venöz port, girişimsel radyoloji, kanser, enfeksiyon.

\section{Abstract}

Aim: The aim of this study is to determine the frequency of reasons for port removal in a single center, to identify the risk factors associated with port-related infection and the factors that affect the patency period of the ports.

Materials and Methods:154 patients with port removal from January 2005 to May 2017 were included in the study. The characteristics of these patients, their clinical diagnoses, reasons for port removal, microbiological data and patency periods were retrospectively investigated. The Chi-square test was used to compare the risk factors associated with port-related infection, and the Mann-Whitney $U$ test was used to compare the factors affecting the patency period.

Results: $51.3 \%$ of the patients were female, $48.7 \%$ were male (mean age $55.1 \pm 15)$. The most frequent (53.2\%) reason for port removal was found to be infection. It was determined that gender, age, malignancy type and having digestive tract cancer did not affect the infection frequency significantly. The most common pathogen (20.9\%) was found to be Staphylococcus aureus in the cultures of infected patients. It was found that gender, age, malignancy type and having digestive tract cancer did not significantly affect the patency period of the ports, however, infection significantly shortened this period.

Conclusion: Ports are removed due to infection in more than half of the patients with cancer. Infection significantly shortens the patency period of ports.

Keywords: Central venous port, interventional radiology, cancer, infection.

\author{
Yazışma Adresi: Fatih Uzunkaya \\ Ondokuz Mayıs Üniversitesi Tıp Fakültesi, Radyoloji Anabilim \\ Dalı, Samsun, Türkiye \\ Makalenin Geliş Tarihi: 16.10.2017 Kabul Tarihi:15.01.2018
}




\section{Giriş}

Kanser hastaları kemoterapi ilaçlarının güvenle uygulanabileceği, santral venöz erişim sağlayan, uzun ömürlü kateterlere intiyaç duyarlar. Bu amaçla geliştirilen santral venöz portlar, gerektiğinde parenteral nutrisyon ve kan ürünlerinin uygulanabilmesine ve kan örneklemelerinin yapılabilmesine de imkân verir. Aynı zamanda kolay erişilebilir ve kolay yerleştirilebilir olmaları sayesinde portlar onkoloji pratiğinde uzun yıllardır yaygın şekilde kullanılmaktadır $(1,2)$. Port kullanımı ile kanser hastalarının yaşam kalitesinin arttığı, enfeksiyon riskinin ve kateterle ilişkili trombotik komplikasyonların azaldığı gösterilmiştir (3). Bununla birlikte, portların tümüyle komplikasyondan uzak olduklarını söylemek mümkün değildir. Uzun dönemde port işlev bozukluğu, port ile ilişkili venöz tromboz, enfeksiyon ve ekstravazasyon hasarı gibi baz komplikasyonlar görülebilmektedir (4). Bu komplikasyonların arasında port ile ilişkili enfeksiyon en sık görülen komplikasyondur ve port yerleştirilen hastaların \%3-10'unda enfeksiyon geliştiği bildirilmektedir (5-8). Başta enfeksiyon olmak üzere bu gibi komplikasyonlar genellikle portların çıkarılmasını zorunlu kılmaktadır. Aksi taktirde gerekli şekilde çıkarılmayıp yerinde bırakılan komplike olmuş portların daha ciddi klinik sonuçlara neden olabileceği bilinmektedir (8).

$\mathrm{Bu}$ çalışmada, hastanemizde 12 yıllık süreçte yapılmış olan port çıkarılması işlemlerini retrospektif olarak analiz ederek, portların çıkarılma nedenlerinin sıklıklarını ortaya koymayı, port kaynaklı enfeksiyon ile ilişkili risk faktörlerini tespit etmeyi ve portların açık kaldığı süreyi etkileyen faktörleri belirlemeyi amaçladık.

\section{Gereç ve Yöntem}

Hastanemizde, 1 Ocak 2005 ile 31 Mayıs 2017 tarihleri arasında port çıkarma işlemi yapılmış hastalar retrospektif olarak analiz edildi. Bunun için hastanemizin dijital arşiv programı üzerinden ilgili tarihler girilerek "subkutan port çıkarılması işlemi" başlıklı kayıtlar tarandı. Bu kapsamda 160 hasta için bu başlık altında istem yapıldığı, ancak bunlardan 6 tanesi için istem yapılmış olmakla birlikte çıkarma işleminin gerçekleştirilmediği tespit edildi ve bu nedenle bu hastalar çalışma dışı bırakıldı. Subkutan port çıkarılması işleminin yapıldığı kesinleşen 154 hasta çalışmaya dahil edildi.

Çalışmaya dahil edilen hastaların yaşları, cinsiyetleri, klinik tanıları, portların çıkarılma nedenleri ve açık kaldıkları süreler araştırıldı. Portların çıkarılma nedeni öncelikle "Subkutan port çıkarılması işlemi" başlıklı işlem raporlarından öğrenilmeye çalışıldı. İşlem raporundan çıkarma nedeninin tespit edilememesi halinde, ilgili hastaya ait anamnez notları, epikriz raporları veya konsültasyon kayıtları çıkarma nedenini tespit etmek için ayrıntılı olarak gözden geçirildi. Bu kapsamda çıkarma işlemi öncesi klinik seyrinde ateş bulgusu olan ve ateş odağını göstermek için alınan kültürlerinin herhangi birinde (kan, kateter veya eksüda kültürü) patojen mikroorganizma üremiş olguların port çıkarma nedeni enfeksiyon olarak kaydedildi. Kemoterapinin bittiği anlaşılan hastalarda çıkarma nedeni tedavi programının tamamlanması olarak kaydedildi. Port çıkarma nedeni enfeksiyon olarak belirlenen tüm olguların bu klinikle alakalı kültür çalışmalarında izole edilmiş olan patojenlerin sıklıkları belirlendi. Portların açık kaldığı süreleri tespit etmek için, çıkarma işlemi ile kronoloji ve yerleşim yeri itibariyle uyumluluk gösteren yerleştirme işlemlerinin tarihleri belirlendi. Bu iki işlemin tarihleri arasındaki fark ay cinsinden hesaplandı. Çok az sayıda hastaya port revizyonu yapılmış olduğundan ve revizyondan kısa bir süre sonra çıkarma işlemi yapıldığından bu hastalar için port açık kalma süreleri bir bütün olarak değerlendirildi.

Port çıkarma nedeni belirlenemeyen olgular (43 olgu), port kaynaklı enfeksiyon ile ilişkili risk faktörlerinin analizinde tüm değişkenler için değerlendirme dışı bırakıldı. Yine, port yerleştirme tarihi tespit edilemeyen olgular (38 olgu), portların açık kaldığı süreyi etkileyen faktörlerin analizinde tüm değişkenler için değerlendirme dışında tutuldu. Port kaynaklı enfeksiyon ile ilişkili risk faktörlerini karşılaştırmak için Ki-kare testi, portların açık kaldığı süreyi etkileyen faktörleri karşılaştırmak için ise Mann-Whitney $U$ testi kullanıldı. 0,05'ten küçük $p$ değerleri istatistiksel olarak anlamlı kabul edildi.

\section{Bulgular}

Çalışma grubumuzdaki hastaların \%51,3'ü kadın,

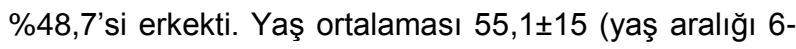
84) olarak hesaplandı.

Hastalarımıza ait tanıların başında $(\% 67,5)$ sindirim kanalı kanserlerinin (özofagus ve mide kanserleri ile kolorektal kanserler) geldiği görüldü. Tek bir hastada tanının kanser dışı bir hastalık (Bartter Sendromu) olduğu ve bu hastada portun parenteral nutrisyon için kullanıldığı tespit edildi (Tablo-1).

Hastalarımızın \%72,1'inde portların çıkarılma nedeni tespit edilebilmiş olup, en sık çıkarma nedeni $(\% 53,2)$ enfeksiyon olarak bulundu. Bunu \%15,3 oranla tedavi programının tamamlanması takip etmekteydi (Tablo-2).

Enfeksiyon nedeniyle portu çıkarılan 59 hastanın \%75'inde mikrobiyolojik kültür sonucu mevcut iken bunların da \%80'inde üreme olduğu tespit edildi. Kültürlerde en sık $(\% 20,9)$ izole edilen patojenin Staphylococcus aureus olduğu belirlendi. Grup olarak en sık $(\% 41,8)$ izole edilen patojenlerin Gram-pozitif kok ailesine mensup olduğu görüldü. Bunları Gram-negatif basillerin takip ettiği belirlendi $(\% 37,2)$. Toplamda mayaların $S$. aureus ile eşit oranda üretildiği tespit edildi (Tablo-3). Kültürlerinde üreme tespit edilen hastaların \%13,3'ünde iki, \%3,33'ünde üç farklı mikroorganizma izole edildiği görüldü. 
Cinsiyet, yaş ve malignite tipi (solid tümör ya da hematolojik malignite) gibi faktörler ile portun çıkarılma nedeninin enfeksiyon olması arasındaki ilişki düzeyi değerlendirildiğinde kadınlarda, yaşı 40'ın altında olanlarda ve hematolojik malignite bulunan hastalarda portların nispeten daha yüksek bir oranda enfeksiyon nedeniyle çıkarılmış olduğu, ancak sayılan bu faktörlerin enfeksiyon sıklığı açısından istatistiksel olarak anlamlı bir farklılığa neden olmadığı görüldü $(p>0,05)$. Sindirim kanalı kanseri tanısının çalışma grubumuzdaki hastaların büyük bir çoğunluğunun ortak tanısı olması nedeniyle bu malignite alt tipi ile portun çıkarılma nedeninin enfeksiyon olması arasındaki ilişki düzeyi araştırıldı. Diğer malignite tiplerinden herhangi birine sahip olguların tümü ile karşılaştırıldığında sindirim kanalı kanserine sahip olgularda portların nispeten daha yüksek bir oranda enfeksiyon nedeniyle çıkarılmış olduğu, ancak her iki grup arasında enfeksiyon sıklığı açısından istatistiksel olarak anlamlı bir fark bulunmadığı tespit edildi $(p>0,05)$ (Tablo-4).

Tablo-1. Hastaların Demografik Özellikleri.

\begin{tabular}{lc}
\hline & $\mathbf{n}$ \\
\hline Yaş ortalaması (aralık) & $55,1 \pm 15(6-84)$ \\
Cinsiyet & \\
Kadın & $79(\% 51,3)$ \\
Erkek & $75(\% 48,7)$ \\
Malignite tipi & \\
Solid tümör & $144(\% 93,5)$ \\
Sindirim kanalı kanserleri & $104(\% 67,5)$ \\
Hepatosellüler kanser & $1(\% 0,6)$ \\
Pankreas kanseri & $3(\% 1,9)$ \\
Akciğer kanseri & $3(\% 1,9)$ \\
Meme kanseri & $18(\% 11,7)$ \\
Jinekolojik kanserler & $6(\% 3,9)$ \\
Baş ve boyun kanserleri & $7(\% 4,5)$ \\
Diğer & $3(\% 1,9)$ \\
Hematolojik maligniteler & $9(\% 5,8)$ \\
Lösemi & $3(\% 1,9)$ \\
Lenfoma & $4(\% 2,6)$ \\
Multiple myeloma & $1(\% 0,6)$ \\
Diğer etiyolojiler & $1(\% 0,6)$ \\
Toplam & $154(\% 100)$ \\
\hline
\end{tabular}

Tablo-2. Portların Çıkarılma Nedenleri.

\begin{tabular}{lc}
\hline Neden & $\mathbf{n}^{*}(\%)$ \\
\hline Enfeksiyon & $59(53,2)$ \\
Tedavi programının & $17(15,3)$ \\
tamamlanması & $2(1,8)$ \\
Fibrin kılıf & $11(9,9)$ \\
Ven trombozu & \\
Dislokasyon & \\
$\quad$ Kateter & $3(2,7)$ \\
$\quad$ Rezervuar & $1(0,9)$ \\
Tıkanma & $6(5,4)$ \\
Ekstravazasyon & $2(1,8)$ \\
Ciltte açılma & $7(6,3)$ \\
Hasta kaynaklı & $3(2,7)$ \\
Toplam & $111(100)$ \\
\hline${ }^{*}$ Portun çıkarılma nedeni bilinen olgu sayısı
\end{tabular}

Tablo-3. Portu Enfeksiyon Nedeniyle Çıkarılan Hastalardan İzole Edilen Mikroorganizmalar.

\begin{tabular}{lc}
\hline Mikroorganizma & $\mathbf{n}(\%)$ \\
\hline Gram-pozitif kok & $18(41,8)$ \\
Staphylococcus aureus & $9(20,9)$ \\
Koagülaz-negatif Staphylococci & $8(18,6)$ \\
Staphylococcus epidermidis & $3(6,9)$ \\
Staphylococcus haemolyticus & $3(6,9)$ \\
Staphylococcus hominis & $2(4,6)$ \\
Enterococcus faecium & $1(2,3)$ \\
Gram-negatif basil & $16(37,2)$ \\
Escherichia coli & $2(4,6)$ \\
Klebsiella sp. & $4(9,3)$ \\
Klebsiella pneumonia & $3(6,9)$ \\
Enterobacter cloacae & $4(9,3)$ \\
Pantoea dispersa & $2(4,6)$ \\
Shewanella putrefaciens & $1(2,3)$ \\
Stenotrophomonas maltophilia & $1(2,3)$ \\
Pseudomonas sp. & $2(4,6)$ \\
Maya & $9(20,9)$ \\
Candida albicans & $8(18,6)$ \\
Candida parapsilosis & $1(2,3)$ \\
Toplam & $43(100)$ \\
\hline
\end{tabular}

Tablo-4: Port Kaynaklı Enfeksiyon ile İlişkili Risk Faktörlerinin Analizi.

\begin{tabular}{lccc}
\hline Değişken & $\begin{array}{c}\text { Toplam, } \\
\mathbf{n}^{*}\end{array}$ & $\begin{array}{c}\text { Enfeksiyon, } \\
\mathbf{n}(\%)\end{array}$ & $\mathbf{p}^{\#}$ \\
\hline Cinsiyet & & & \\
$\quad$ Kadın & 56 & $31(55,4)$ & \\
$\quad$ Erkek & 55 & $29(52,7)$ & $>0,05$ \\
Yaş & & & \\
$\quad 40$ & 16 & $10(62,5)$ & \\
$40-65$ & 66 & $36(54,5)$ & \\
$>65$ & 29 & $14(48,3)$ & $>0,05$ \\
Malignite tipi & & & \\
$\quad$ Solid tümör & 105 & $56(53,3)$ & \\
$\quad$ Hematolojik malignite & 5 & $3(60)$ & $>0,05$ \\
$\quad$ Malignite alt tipi & & & \\
$\quad$ Sindirim kanalı & 74 & $40(54,1)$ & \\
$\quad$ kanserleri & 36 & $19(52,7)$ & $>0,05$ \\
$\quad$ Diğer maligniteler & 36 & \\
\hline *Portun çıkarıma nedeni bilinen olgu sayısı & & \\
\#p değeri Ki-kare testi ile hesaplanmıştı. &
\end{tabular}

Çalışmaya dahil edilen hastaların \%75,3'ü için (116 hasta) çıkarma işlemine konu olan portun yerleştirildiği tarih belirlenmiş olup, bu hastalar için portların açık kaldığı süre; minimum 0,25 ay, maksimum 120 ay olarak hesaplandı (ortalama süre $15,5 \pm 19,9$ ay, ortanca süre 9 ay). Geriye kalan 38 hastanın portu muhtemelen tarafımızca takılmadığı için yerleştirme tarihleri tespit edilemedi. Portların açık kalma süresi ile cinsiyet, yaş, malignite tipi ve sindirim kanalı kanserine sahip olma gibi faktörlerin ilişkisi değerlendirildiğinde, sayılan bu faktörlerin portların açık kaldığı süreyi istatistiksel olarak anlamlı derecede etkilemedikleri görüldü $(p>0,05)$. Bununla birlikte, enfeksiyon gerekçesiyle portu çıkarılmış hastalarla, portu tedavi programı tamamlandığı için 
çıkarılmış hastalar karşılaştırıldığında, enfeksiyon gerekçesiyle portu çıkarılmış hastalarda portların daha kısa sürelerle açık kaldığı ve aradaki farkın istatistiksel olarak da anlamlı olduğu tespit edildi (ortanca süre 7 aya karşılık 19 ay, $p=0,001$ ) (Tablo-5).

Tablo-5. Portların Açık Kaldığı Süreyi Etkileyen Faktörlerin Analizi.

\begin{tabular}{|c|c|c|c|c|c|}
\hline \multirow{2}{*}{ Değişken } & \multirow{2}{*}{$\mathbf{n}^{\star}$} & \multirow{2}{*}{$\begin{array}{l}\text { Ortanca } \\
\text { süre (ay) }\end{array}$} & \multicolumn{2}{|c|}{ Çeyrekler (ay) } & \multirow{2}{*}{$\mathbf{p}^{\#}$} \\
\hline & & & 25 & 75 & \\
\hline \multicolumn{6}{|l|}{ Cinsiyet } \\
\hline Kadın & 60 & 9 & 4 & 19 & \multirow{2}{*}{$>0,05$} \\
\hline Erkek & 56 & 8 & 3 & 17 & \\
\hline \multicolumn{6}{|l|}{ Yaş } \\
\hline$<65$ & 84 & 9 & 2,25 & 16,75 & \multirow{2}{*}{$>0,05$} \\
\hline$\geq 65$ & 32 & 9 & 4 & 31,75 & \\
\hline \multicolumn{6}{|l|}{ Malignite tipi } \\
\hline Solid tümör & 110 & 9 & 3 & 19 & \multirow{2}{*}{$>0,05$} \\
\hline Hematolojik & 5 & 9 & 1,5 & 22 & \\
\hline \multicolumn{6}{|l|}{ Malignite alt tipi } \\
\hline Sindirim kanalı & 77 & 9 & 4 & 21,5 & \multirow{2}{*}{$>0,05$} \\
\hline Diğer & 38 & 9 & 1,75 & 16,25 & \\
\hline \multicolumn{6}{|l|}{ Çıkarma nedeni } \\
\hline Enfeksiyon & 46 & 7 & 1 & 15,25 & \multirow[b]{2}{*}{0,001} \\
\hline $\begin{array}{l}\text { Tedavinin } \\
\text { tamamlanması }\end{array}$ & 13 & 19 & 10,5 & 54,5 & \\
\hline
\end{tabular}

${ }^{*}$ Portun açık kaldığı süre bilinen olgu sayısı.

\#Mann-Whitney $U$ testi ile hesaplanmıştır.

\section{Tartışma}

İlk öncüleri Broviac ve Hickman tipi, kısmen implante edilebilir santral venöz kateterler olan portlar daha güvenli tedavilerin yapılabilmesine olanak sağlamış, hastalara daha rahat hareket edebilme imkânını vermiş ve kozmetik kaygıları azaltmıştır (1,9-11). Tüm medikal cihazlar gibi portlar için de ideal olanı, yerleştirildiğ andan tedavi bitiminde çıkarılana kadar sorunsuz bir şekilde işlev görebilmeleridir (3). Ancak portlar da bütünüyle komplikasyondan uzak değildirler. Bir dizi çalışma ile, \%1,6-28 gibi geniş bir oran aralığında portların komplike oldukları gösterilmiştir $(1,4,12,13)$. Enfeksiyon, ven trombozu, portun tıkanması, port haznesinin veya kateterinin yer değiştirmesi, kemoterapi ajanının ekstravazasyonu, fibrin kılıf oluşumu ya da ciltte açılma gibi birtakım komplikasyonlar ortaya çıkabilir $(1,4)$. Bunlar arasında yüzde 10'lara varan oranlar ile en sık görülen komplikasyon enfeksiyondur (5-8). Başta enfeksiyon olmak üzere bu gibi komplikasyonlar genellikle portu kullanılamaz hale getirir ve portun vücuttan uzaklaştırılması kaçınılmaz olur. Aksi takdirde, enfeksiyonun ciddi sepsis veya septik şoka ilerlemesi ya da ven trombozunun yaygınlaşarak superior vena kava sendromuna yol açması örneklerinde olduğu gibi birtakım istenmeyen kötü sonuçlarla karşılaşılabilir (8). Bununla birlikte, portlar sadece komplike oldukları zaman çıkarılmak durumunda kalmazlar. Kemoterapi programının bitişi veya estetik kaygı gibi hasta kaynaklı birtakım nedenlerle de çıkarma işlemi yapılabilir. Durum böyle olsa da enfeksiyon birçok çalışmada uzun dönemde (3 aydan daha sonrası) portların başlıca çıkarılma nedeni olarak gösterilmektedir $(3,4,6,14)$. Biacchi ve ark. (3) serisinde, enfeksiyon \%47,6 oranla en sık port çıkarma nedeni olarak bildirilmektedir. Biz de serimizde benzer şekilde, enfeksiyonun \%53,2 oranla en sık çıkarma nedeni olduğunu tespit ettik. Çalışma grubumuzdaki hastaların sayıca ancak \%11'inin portu tedavi programı tamamlandığı için çıkarılmış olup, tedavi programının tamamlanması, çıkarma nedenleri arasında enfeksiyonun ardından ikinci sırada gelmektedir. Ancak bizimkine benzer çalışmalardan farklı olarak Ji ve ark. (1) serisinde, port çıkarma nedenleri arasında birinci sırada tedavi programının tamamlanması (349/426), ikinci sırada ise enfeksiyon (45/426) gösterilmektedir. Port kullanımında hedef, tedavi programı tamamlanana kadar portun sorunsuz bir şekilde çalışması ve sonrasında intiyaç kalmadığından çıkarılmasıdır. Kanser hastaları gibi immünitesi baskılanmış, otonomisi bozulmuş ve bu yüzden enfeksiyona yatkın hale gelmiş hasta grubunda bu hedefi tutturmanın çoğu zaman mümkün olmadığını anlaşılmaktadır $(3,4,6,14)$.

Portların çıkarılmasını zorunlu kılan etmenlerin başında gelen enfeksiyon ile ilişkili risk faktörlerini değerlendiren çalışmalarda cinsiyet, yaş, kanser tipi, portun anatomik konumu, yerleştirme yöntemi, kullanım amacı, kullanım sıklığı ve kemoterapinin veriliş amacı gibi birtakım unsurlar üzerinde durulmuştur $(1,3,8,12,14,15)$. Schwarz ve ark. (12) çalışmasında, erkek cinsiyetin yüksek enfeksiyon oranı ile ilişkili bulunduğu belirtilmektedir. Bazı çalışmalarda ise cinsiyetin enfeksiyon görülme sıklığı ile ilişkili olmadığı söylenmektedir $(1,8,14)$. Genç yaşın (40 yaş ve altı) enfeksiyon için risk artışına neden olduğunu bildiren çalışmalar mevcuttur $(1,8)$. Bunun aksine Shim ve ark. (14) çalışmasında yaşın enfeksiyon gelişimini etkileyen bir faktör olmadığı belirtilmektedir. Li ve ark. (1) hematolojik malignitenin ve palyatif kemoterapinin enfeksiyon riskini artırdığını bildirmişlerdir. Benzer şekilde iki farklı çalışmada hematolojik malignitenin enfeksiyon için risk faktörü olduğu söylenmektedir $(12,14)$. Ayrıca portun sık kullanılması, portun parenteral beslenme için kullanılması, port rezervuarında trombüs oluşması, zayıf otonomi ve metastatik kanser port enfeksiyonu ilişkili risk faktörleri olarak tanımlanmaktadır $(8,16)$. Bizim çalışma grubumuzdaki hastalardan elde edebildiğimiz verilerden ortaya çıkan sonuçlar ise kadınlarda, yaşı 40'ın altında olanlarda ve hematolojik malignite bulunan hastalarda portların nispeten daha yüksek bir oranda enfeksiyon nedeniyle çıkarılmış olduğu, ancak cinsiyetin, yaşın ve malignite tipinin enfeksiyon sıklığını anlamlı derecede etkilemediğini göstermektedir. Benzer şekilde sindirim kanalı kanserine sahip hastalardaki portlar nispeten daha yüksek bir oranda enfeksiyon nedeniyle çıkarılmış olsa da malignite alt tipinin sindirim kanalı kanseri olmasının enfeksiyon sıklığını anlamlı derecede etkilemediği görülmüştür. 
Port enfeksiyonu oluşumunda, port septumunun defalarca delinmesini takiben ortaya çıkan lümen içi kontaminasyon en önemli etken olarak gösterilmektedir $(8,17)$. Bu mekanizma aynı zamanda deri florasının üyeleri arasında bulunan koagülaz negatif stafilakokların ve $S$. aureus'un port kaynaklı enfeksiyonlarda neden en sık izole edilen patojenler olduklarını da izah etmektedir $(2,8,18)$. Ayrıca yayınlarda Gram-negatif basillerin ve mayaların artan öneminden bahsedilmektedir $(2,8,19)$. Bizim sonuçlarımız da bu literatür verileri ile uyumlu olup, serimizde $S$. aureus ile birlikte koagülaz negatif stafilakoklar toplamda en sık izole edilen patojenler olmuştur. Bunları grup olarak Gram-negatif basiller takip ederken mayaların kültürlerin önemli bir kısmında patojen olarak üretildiği görülmüştür.

Portların uzun ömürlü tıbbi cihazlar oldukları bilinmektedir. Biacchi ve ark. (3) çalışmasında, 12 yıl gibi uzun bir süreden bahsedilmektedir. Bizim serimizde de 10 yılın sonunda portu çıkarılan bir olgu bulunmaktadır. Portların açık kalma süresi ile ilişkili faktörleri konu eden çalışmalar incelendiğinde, Biacchi ve ark. (3) yerleştirme yönteminin (cut-down ya da Seldinger yöntemi) bu süre üzerinde anlamlı bir etkiye sahip olmadığını bildirmektedir. Arıbaş ve ark. (20) çalışmasında ise port açık kalma süresi üzerinde yegâne etkili faktörün malignitenin yerleşim bölgesi olduğu ifade edilmektedir. Bizim sonuçlarımız ise cinsiyetin, yaşın, malignite tipinin ve sindirim kanalı kanserine sahip olmanın portların açık kaldığı süreyi anlamlı derecede etkileyen faktörler olmadıklarını göstermektedir. Ancak, enfeksiyon gerekçesiyle portu çıkarılmış hastalarda, portu tedavi programı tamamlandığı için çıkarılmış hastalara kıyasla port açık kalma süresinin önemli ölçüde daha kısa olduğu görülmüştür. $\mathrm{Bu}$ durum muhtemelen enfeksiyonun diğer port komplikasyonu çeşitlerine nispetle daha hızlı ve şiddetli bulgu vermesi dolayısıyla erkenden tespit edilmesine, tespitinin ardından konservatif tedaviye yanıt alınamadığı takdirde en kısa süre içerisinde çıkarma işleminin yaptırılmasına bağlı olabilir. Aksi takdirde port kaynaklı enfeksiyonun yüksek mortalite ve morbidite ile sonuçlanacağı bilinmektedir (2). Oysa tedavi programı tamamlandığı için portun çıkarılmasının istendiği durumlarda çıkarma işleminin böyle hızlıca yapılması için uğraşılmamaktadır. Dolayısıyla portun çıkarılması vakit alabilmektedir.
Sonuç olarak süreler arasında böyle bir farkın çıkmış olması anlaşılabilir bir durumdur.

Çalışmamızın retrospektif nitelikte olması dolayısıyla birtakım kısıtıılıları bulunmaktadır. Bunların başında veri eksikliği gelmektedir. Örneğin, çalışmaya dahil edilen hastaların yaklaşık 4'te 1'inde port çıkarma nedeni tespit edilememiştir. $\mathrm{Bu}$ oran benzer çalışmalar ile kıyaslandığında bir miktar yüksek kalmıştır. Yine hastaların 4'te 1'inde port açık kalma süresi belirlenememiştir. Bu verilerin eksikliği bunlardan elde edilen sonuçları etkilemiş olabilir. Ancak bu verilerdeki eksikliğinin yıllara göre randomize dağılım göstermesinden ötürü bias oluşturacak nitelikte olduğunu düşünmüyoruz. Bunlara ilaveten, son birkaç yıl içerisinde işlem yapılan hastaların haricinde, çıkarılan portların marka ve modeli belirlenememiştir. Bu nedenle çalışmamızda materyale göre gruplandırma ve materyal ile port çıkarılma nedeni, enfeksiyon sıklığı veya port açık kalma süresi arasındaki ilişkinin değerlendirilmesi gibi ek analizler yapılamamıştır. Veri eksikliğinin yanında çalışmamızla ilgili diğer bir kısıtııı olarak çalışma grubumuzdaki hasta sayısının nispeten az olması gösterilebilir. Aynı çalışmanın daha fazla sayıda hastayla ve prospektif nitelikte yapılması halinde daha verimli olacağı aşikârdır.

\section{Sonuç}

Bu çalışma ile, portların en sık enfeksiyon gerekçesiyle çıkarıldığı tespit edildi. Cinsiyetin, yaşın, malignite tipinin ve sindirim kanalı kanserine sahip olmanın port kaynaklı enfeksiyon sıklığını anlamlı derecede etkilemediği belirlendi. Enfeksiyon gelişen hastaların kültürlerinde izole edilen patojenlerin ağırlıklı olarak deri florasının doğal üyelerinden oluştuğu görüldü. Cinsiyetin, yaşın, malignite tipinin ve sindirim kanalı kanserine sahip olmanın portların açık kaldığı süreyi anlamlı derecede etkilemediği, buna karşın enfeksiyonun portların açık kaldığı süreyi önemli ölçüde kısalttığı tespit edildi.

Sonuç olarak, kanser hastalarının yarısından fazlasının portu enfeksiyon nedeniyle çıkarılmaktadır. Enfeksiyon, portların açık kaldığı süreyi önemli ölçüde kısaltmaktadır.

\section{Açıklama}

Yazarların metinde yer alan materyalle ilgili hiçbir mali çıkarı yoktur.

\section{Kaynaklar}

1. Ji L, Yang J, Miao J, Shao Q, Cao Y, Li H. Infections related to totally implantable venous-access ports: Long-term experience in one center. Cell Biochem Biophys 2015;72(1):235-40.

2. Lebeaux D, Larroque B, Gellen-Dautremer J, et al. Clinical outcome after a totally implantable venous access port-related infection in cancer patients: A prospective study and review of the literature. Medicine 2012;91(6):309-18.

3. Biacchi D, Sammartino P, Sibio S, et al. Does the implantation technique for totally implantable venous access ports (TIVAPS) influence long-term outcome? World J Surg 2016;40(2):284-90.

4. Kurul S, Saip P, Aydin T. Totally implantable venous-access ports: Local problems and extravasation injury. Lancet Oncol 2002;3(11):684-92. 
5. Barbetakis N, Asteriou C, Kleontas A, Tsilikas C. Totally implantable central venous access ports. Analysis of 700 cases. J Surg Oncol 2011;104(6):654-6.

6. Fischer L, Knebel P, Schröder S, et al. Reasons for explantation of totally implantable access ports: A multivariate analysis of 385 consecutive patients. Ann Surg Oncol 2008;15(4):1124-9.

7. Hsieh $\mathrm{CC}$, Weng $\mathrm{HH}$, Huang WS, et al. Analysis of risk factors for central venous port failure in cancer patients. World $\mathrm{J}$ Gastroenterol 2009;15(37):4709-14.

8. Chang L, Tsai JS, Huang SJ, Shih CC. Evaluation of infectious complications of the implantable venous access system in a general oncologic population. Am J Infect Control 2003;31(1):34-9.

9. Hickman RO, Buckner CD, Clift RA, Sanders JE, Stewart P, Thomas ED. A modified right atrial catheter for access to the venous system in marrow transplant recipients. Surg Gynecol Obstet 1979;148(6):871-5.

10. Broviac JW, Cole JJ, Scribner BH. A silicone rubber atrial catheter for prolonged parenteral alimentation. Surg Gynecol Obstet 1973;136(4):602-6.

11. Vidal M, Genillon JP, Forestier E, et al. Outcome of totally implantable venous-access port-related infections. Med Mal Infect 2016;46(1):32-8

12. Schwarz RE, Groeger JS, Coit DG. Subcutaneously implanted central venous access devices in cancer patients: A prospective analysis. Cancer 1997;79(8):1635-40.

13. Kock HJ, Pietsch M, Krause U, Wilke H, Eigler FW. Implantable vascular access systems: Experience in 1500 patients with totally implanted central venous port systems. World J Surg 1998;22(1):12-6.

14. Shim J, Seo TS, Song MG, et al. Incidence and risk factors of infectious complications related to implantable venous-access ports. Korean J Radiol 2014;15(4):494-500.

15. Lebeaux D, Fernández-Hidalgo N, Chauhan A, et al. Management of infections related to totally implantable venous-access ports: challenges and perspectives. Lancet Infect Dis 2014;14(2):146-59.

16. Penel N, Neu JC, Clisant S, Hoppe H, Devos P, Yazdanpanah Y. Risk factors for early catheter-related infections in cancer patients. Cancer 2007;110(7):1586-92.

17. Vescia S, Baumgärtner AK, Jacobs VR, et al. Management of venous port systems in oncology: A review of current evidence. Ann Oncol 2008;19(1):9-15.

18. Groeger JS, Lucas AB, Thaler HT, et al. Infectious morbidity associated with long-term use of venous access devices in patients with cancer. Ann Intern Med 1993;119(12):1168-74

19. Chen WT, Liu TM, Wu SH, Tan TD, Tseng HC, Shih CC. Improving diagnosis of central venous catheter-related bloodstream infection by using differential time to positivity as a hospital-wide approach at a cancer hospital. J Infect 2009;59(5):317-23.

20. Aribas BK, Tiken R, Aribas $\mathrm{O}$, et al. Factors on patency periods of subcutaneous central venous port: long-term results of 1.408 patients. Iran J Radiol 2017;14(2):e36816. 